Plummer Alston "Al" Jones, Jr.,

\section{Unity v. Diversity: The Dilemma of Professionalism}

e have grown up knowing the motto of the Three Musketeers: All for One, One for All. Now we more fully understand that the musketeers were articulating in rather elegant shorthand their endorsement of the concepts of group unity and group diversity.

Most would agree that the North Carolina Library Association's strength lies in the fact that it is a very diverse organization offering a forum for public librarians, school librarians, and academic librarians as well as librarians in various specializations in librarianship. NCLA has consistently advocated that libraries need to change to accommodate new user groups and meet their special emerging needs - even to the point of creating a new membership organization (round table usually) to serve a new group.

Unfortunately, NCLA has not been as successful in achieving the concept of group unity. To put it quite simply, we as members of a diverse organization have still not learned to collaborate - to work together to solve common problems. Most of our members feel extreme loyalty for sections or round tables that address issues affecting them individually and collectively. What appears on the surface to be loyalty can lead inexorably to the belief that NCLA is superfluous to the needs of a particular interest group.

I personally view NCLA as the glue that binds all of this wonderful diversity into a powerful unified professional organization. If we work together, NCLA has the clout to affect societal change through the political process with the North Carolina General Assembly at the state level. Since NCLA is the state chapter of the American Library Association, North Carolina librarians can offer a united voice that will be heard at the national level also.

I would like for NCLA members to see NCLA not as superfluous or even part of the problem, but as part of the solution. I believe that NCLA is dealing with a societal program that is bigger even than NCLA - a widespread distrust of large organizations - a problem not only statewide, but also nationwide and even on an international scale. The dissolution of this widespread distrust must be accomplished one organization at a time, one state at a time. Let's work together to make NCLA a model for the other state library associations to emulate.

ALA President in the late 1970s, Eric Moon, formerly editor of Library Journal and retired publisher and head of Scarecrow Press, called for the reform of ALA's organizational structure. In Moon's opinion, ALA's divisions, including the Association of College and Research Library (ACRL), the Public Library Association (PLA), and the American Association of School Librarians (AASL), to name but three of many, were divisive and unwittingly promoted disunity. In a sense, ALA's multitude of divisions is similar to NCLA's wide array of sections and roundtables. The recent breakaway from NCLA of the majority of the former members of the North Carolina Association of School Librarians Section has weakened our voice at the local, state, and national levels. What will happen to NCLA if public librarians or academic librarians choose to leave?

Where is professionalism - our loyalty to the profession of librarianship? I believe that being a professional means putting the needs of all citizens for free libraries and unfettered access to information ahead of even the most noble special interests. 